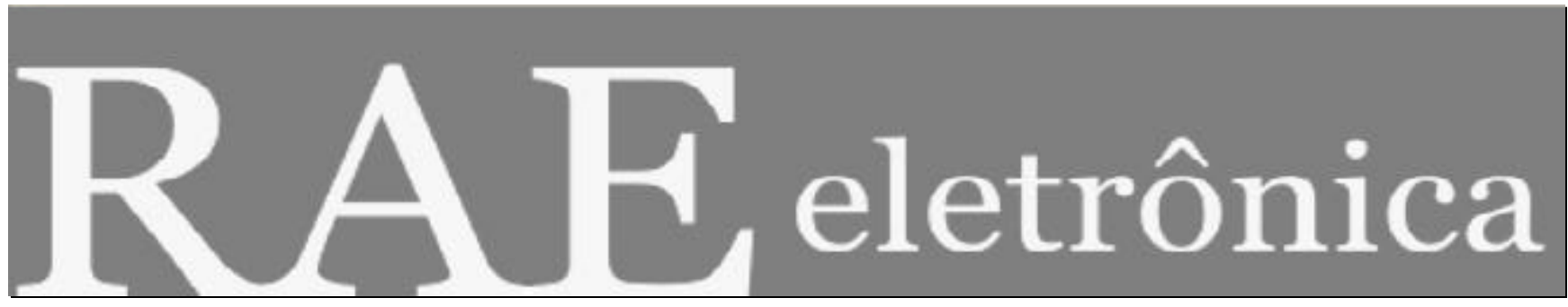

\title{
SONEGAÇÃO TRIBUTÁRIA E COMPLEXIDADE
}

Por:

\section{Roberto N. Sayeg}

RAE-eletrônica, Volume 2, Número 1, jan-jun/2003.

http://www.rae.com.br/eletronica/index.cfm?FuseAction=Artigo \&ID=1359\&Secao=PÚBLICA\&Volume=2\&Numero=1\& $\mathrm{Ano}=2003$

(C) Copyright, 2002, RAE-eletrônica. Todos os direitos, inclusive de tradução, são reservados. É permitido citar parte de artigos sem autorização prévia desde que seja identificada a fonte. A reprodução total de artigos é proibida. Os artigos só devem ser usados para uso pessoal e não-comercial. Em caso de dúvidas, consulte a redação: redacao@ rae.com.br.

A RAE-eletrônica é a revista on-line da FGV-EAESP, totalmente aberta e criada com o objetivo de agilizar a veiculação de trabalhos inéditos. Lançada em janeiro de 2002, com perfil acadêmico, é dedicada a professores, pesquisadores e estudantes. Para mais informações consulte o site www.rae.com.br/eletronica.

\section{RAE-eletrônica}

ISSN 1676-5648

(C2002 Editora: Fundação Getulio Vargas - Escola de Administração de Empresas de São Paulo.
F U N D A C Ã O GETULIO VARGAS

Escola de Adrninistaçäo de Emprasas de São Pă a 


\title{
SONEGAÇÃO TRIBUTÁRIA E COMPLEXIDADE Uma visão multidimensional
}

\section{Roberto N. Sayeg}

Agente Fiscal de Rendas da Secretaria da Fazenda do Estado de São Paulo, Doutor em Comunicação e Cultura pela Universidade Federal do RJ.

E-mail: rnsayeg@fazenda.sp.gov.br

Endereço: Rua Carneiro de Souza, 99 - Taubaté - SP - 12.010-070

Interesses de pesquisa: Refletir sobre o problema da sonegação tributária no Brasil, com o intento maior de melhorar a comunicação entre Governo e sociedade.

\section{RESUMO}

Trata-se de um estudo cujo interesse é refletir acerca da sonegação tributária no cenário brasileiro. A partir de uma abordagem que se propõe chamar de "complexa", voltada a lutar contra esquemas de pensamento simplificadores do real sob análise, o problema da sonegação é subdividido em cinco desafios menores, todos mutuamente associados: detecção; diminuição; prevenção; legitimação e ética. Fica evidente, ao longo da argumentação, a condição de cada um dos desafios influenciar e ao mesmo tempo ser influenciado por todos os outros, gerando um saber sempre incerto e inacabado. Evitando qualquer perspectiva de racionalização absoluta do real, o trabalho deixa fluir um discurso preocupado, antes de tudo, em tratar o problema por meio de um enfoque multidimensional, que evita a ingênua adesão a alguma solução-chave para o problema.

\begin{abstract}
The intention of the article is to discuss tax evasion ocurring on brazilian scenary. Making use of an approach known as "complex", with an interest direct to contest simplifying thinkings related to the subject, the matter of tax evasion is divided into five smaller challenges: detection ; reduction; prevention; legitimacy and ethical. It becomes clear, as long as the reflexion goes on, the condition of each challenge to affect and be affected by the others, conducing to an uncertain and unfinished knowledge. In order to prevent any perspective of an absolute rationalization of real, the article lets go on a thought worried, first of all, to deal with the subject by using a multidimentional approach, in order to avoid an innocent espousal to a definitive solution to the problem.
\end{abstract}

PALAVRAS-CHAVE

Sonegação tributária, tributação, administração pública, mudança organizacional, complexidade.

\section{KEY WORDS}

Tax evasion, taxation, public administration, organizational change, complexity. 


\section{POR UMA ÓTICA DA COMPLEXIDADE}

O trato com a "complexidade" se faz a partir de uma luta permanente e inevitável contra a simplificação. Pode-se dizer que a simplificação é uma tendência natural do pensamento, que deve ser continuamente combatida. A simplificação se operacionaliza, muito freqüentemente, por meio de reduções ou disjunções (MORIN, 1977, p.24). Uma redução pode ser entendida como a efetivação de um princípio de explicação que só leva em conta uma dimensão do real (unidimensionalização). Uma disjunção, por outro lado, se expressa como um isolamento entre duas dimensões. É o caso, por exemplo, de se tentar analisar um determinado objeto (p. ex., o contribuinte) destacando-o, isolando$o$, do meio em que ele se encontra. A conseqüência talvez mais nefasta da simplificação, seja ela disjuntiva ou redutora, é que por meio dela fica camuflada a dificuldade de conceito e de lógica inerente ao esforço humano de entendimento do real.

Fugir à simplificação significa, em outras palavras, rejeitar qualquer pretensão de se levar a termo uma absoluta racionalização do real, em tempo atual ou mesmo como projeção futura, que tenha como suporte elementos estabilizadores da condição humana em sua interação com o mundo. Incerteza, desordem e contradição constituem insumos indissociáveis de um discurso que se pretende "complexo", em detrimento de quaisquer propostas que possam ser apresentadas como soluçõeschave, imbuídas de conceitos capazes de anunciar o alcance de um cenário centrado num desejável (porém irreal) contexto de permanência e estabilidade.

Por outro lado, pensar sob o espectro da "complexidade" não significa abrir mão da expectativa por uma melhoria da vida humana em sociedade, desprezando qualquer idéia de progresso. Todavia, significa reenquadrar a noção de progresso, destituindo-a de seu manto positivista (COMTE,1983) à moda do século XIX, cujo pano de fundo é a idéia-chave de uma inevitável evolução linear da vida humana em sociedade que culmina com um aparato científico-tecnológico capaz de solucionar os problemas humanos. Em outros termos, significa destituir a noção de progresso de qualquer perspectiva salvacionista, fundamentada, ainda que inconsciente para muitos, numa idéia de providência sobrenatural.

As características do pensamento complexo citadas até aqui apontam, pois, na direção de um esforço de análise e de reflexão que busca evitar os riscos da produção de um conhecimento passível de "endurecer", de efeito paralisante, que acabe por distanciá-lo do próprio real que ele, o pensamento complexo, busca interpretar, entender. Desses fatos se pode depreender que o saber gerado pela complexidade se apresenta sempre como um conhecimento inacabado, disposto a acolher novos dados e operar constantes reavaliações da compreensão humana acerca do real sob análise.

\section{UM POSSÍVEL MODELO PARA A REFLEXÃO}

A intenção no presente artigo é a de refletir sobre a questão da sonegação tributária no cenário brasileiro. Como suporte para a discussão, propõe-se aqui uma modelagem pautada por uma divisão do assunto em cinco elementos básicos, todos intimamente associados entre si : detecção ; diminuição ; prevenção ; legitimação e ética. 


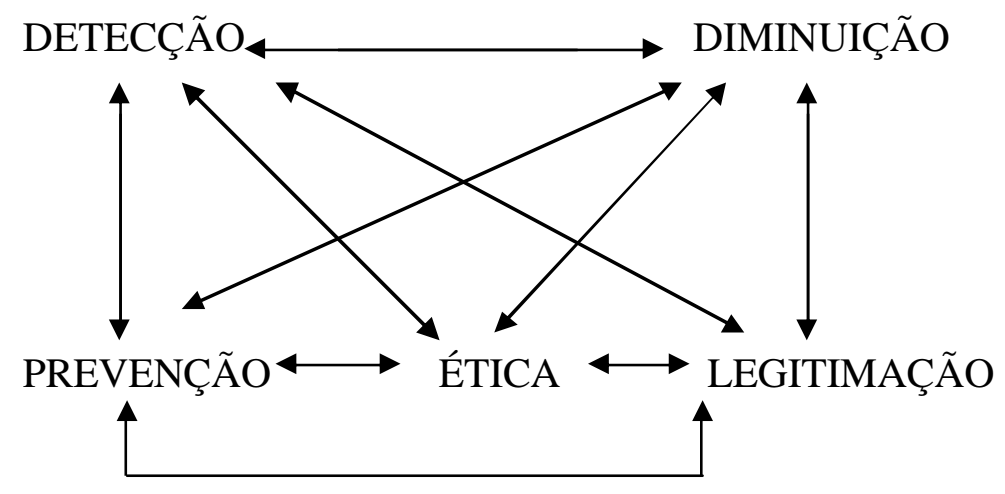

Os três primeiros (detecção, diminuição e prevenção) referem-se diretamente à questão da sonegação, enquanto o quarto elemento (legitimação) lida com a questão da legitimidade do tributo como instituto social. O quinto elemento, o vetor ético, é o único que não se reporta diretamente ao objeto do processo (o tributo), mas aos vários sujeitos do processo (contribuintes e poder público), visto que provoca uma reflexão do ser humano sobre si próprio. Este fato, por si só, determina a importância vital deste elemento, uma vez que o seu desempenho co-produz os resultados alcançados pelos outros quatro elementos.

Os cinco elementos representam, na verdade, desafios a serem enfrentados. $\mathrm{Na}$ sua totalidade, representam uma possível modelagem do problema da sonegação, ainda que um tanto incipiente e rudimentar, mas que, enfim, viabiliza um arcabouço teórico para a reflexão. Tal base de conhecimento, por sua vez, se apresenta como aplicável às várias administrações tributárias (federais/estaduais/municipais), permitindo o surgimento de um "fórum de debates", na forma de um diálogo constante entre elas. Vale ressaltar que a importância dessa base comum reside não apenas na sua condição de disseminadora de conhecimentos, mas também como um estímulo para o fortalecimento de uma consciência acerca do caráter de dependência mútua e solidariedade que deve existir na relação entre os vários níveis governamentais, no que tange às questões de ordem tributária.

A reflexão que aqui está sendo proposta, não obstante possa apresentar, em determinados momentos, um desenvolvimento sem uma "experimentação" correlata, nunca poderá deixar de estar vinculada ao real, ao mundo concreto da relação administração tributária versus contribuinte. Tal reflexão deve estar sempre recebendo insumos do mundo prático, ao mesmo tempo que deve também fomentar a tomada de decisões por parte das administrações tributárias.

Uma contribuição vital da referida reflexão consiste em dar transparência aos paradigmas que sustentam o modus operandi das administrações fazendárias (SAYEG,2001), discutindo o grau de adequação dos mesmos e a necessidade ou não de mudá-los para novas formulações. Tal discussão, por sua vez, cria a possibilidade de um diálogo interno à organização, permitindo que se vislumbre a visão pessoal de cada funcionário quanto ao que ele pensa de si e da sua organização, constituindo-se num valioso instrumento para uma tentativa de maior compartilhamento de idéias e, por decorrência, comprometimento dos funcionários para com os intentos/metas da organização (SENGE,2000).

Dar transparência a paradigmas/modelos mentais que influenciam as mentes individuais de uma organização é condição fundamental para que as organizações sobrevivam de modo salutar. Nem sempre está muito claro para as pessoas que toda e qualquer conduta adotada, por menor ou menos importante que seja, está amparada por uma série de princípios subjetivos, que agrupados traduzem verdadeiros modelos mentais. Em outros termos, o que se quer dizer aqui é que não existe "prática 
pura" no contexto das ações humanas. Ela é típica, isto sim, do animal não humano, em que a ação não é interiorizada, não é refletida, mas mergulhada no imediatismo do aqui e agora.

\section{AMPLITUDE E INTENSIDADE DO MODELO}

Os desafios aqui apresentados têm uma amplitude total. Eles se aplicam a todo e qualquer tributo existente no cenário nacional. Contudo, a intensidade dessa aplicação pode variar bastante, dependendo da natureza e funcionamento do tributo.

Impostos como o estadual IPVA (sobre a propriedades de veículos automotores) e o municipal IPTU (sobre a propriedade territorial urbana), por exemplo, podem ser considerados de baixa complexidade administrativa quando comparados a tributos tais como os federais COFINS, PIS, CSSL, IPI e IPRJ, o estadual ICMS e o municipal ISS. O motivo é que, com exceção do IPVA e do IPTU, todos os outros interferem, de modo contínuo e regular, direta ou indiretamente, sobre o faturamento das empresas em que atuam.

As bases de tributação variam bastante e consistem, em essência, do faturamento empresarial (PIS e COFINS), do lucro empresarial (CSSL e IRPJ), da industrialização de bens (IPI), da prestação de serviços (ISS) e da circulação de mercadoria e prestação de alguns serviços (ICMS). O IPI e o ICMS possuem, todavia, um elemento em comum, a nível de funcionamento, que é o fato de ambos incidirem sobre o "valor adicionado", ou seja, apenas sobre o valor agregado ao produto pela empresa em cada etapa do processo de industrialização/comercialização.

Não obstante as características descritas para os vários tributos, o maior interesse do presente trabalho consiste em diferenciar os tributos do ponto de vista do impacto mercadológico. Contrariamente ao perfil dos dois primeiros (IPVA e IPTU), os outros tributos (PIS, COFINS, CSSL, IRPJ, IPI, ICMS e ISS) incorporam elementos de alto dinamismo e enorme influência econômicomercadológica. Conforme será explicitado mais adiante (no tópico "o desafio da diminuição"), a interferência no faturamento e, por decorrência, no grau de liquidez, acarreta, na prática, uma disfuncionalidade quanto ao uso dos tributos em tela. Isso porque as empresas que os utilizam optam, não raras vezes, por transformá-los em instrumento de competição mercadológica. Mecanismos de redução de pagamento do tributo, ilegais (fraude fiscal) ou mesmo legais (elisão fiscal), são utilizados em meio às transações realizadas como estratégias de competição relativamente às concorrentes que atuam no mesmo setor econômico (círculo de concorrência).

\section{O DESAFIO DA DETECÇÃO}

O desafio da detecção relaciona-se à capacidade de detectar, des-cobrir ( ou seja, tirar o manto que cobre/esconde) as sonegações porventura entranhadas na vida fiscal dos contribuintes. Detectar as sonegações têm sido uma tarefa árdua e cada vez mais difícil para os fiscos envolvidos. O universo econômico-mercadológico contemporâneo, apoiado em sistemas de informação cada vez mais complexos, evolui numa escala sem precedentes, criando um "gap" entre o potencial do ente fiscalizador para detectar a sonegação e o potencial do contribuinte para praticá- la.

Tal fato acarreta a necessidade das administrações tributárias apresentarem uma evolução não apenas do aparato físico-estrutural, como também da capacitação técnica do poder fiscalizador, no sentido de, permanentemente, estarem aptas a fazer frente ao nível de complexidade organizacional, tecnológico e cognitivo intrínseco aos entes fiscalizados. Pode-se dizer que essa equivalência 
caracteriza, com certeza, um importante requisito para que o poder público possa agir com eficiência/eficácia face ao problema da sonegação.

A partir das considerações feitas, pode-se depreender que a questão da detecção requer uma abordagem administrativa típica daquelas voltadas para "sistemas abertos", passível de ser encontrada, por exemplo, no âmbito das teorias estruturalista, sistêmica e contingencial (CHIAVENATO,1993). Isso significa que as organizações fazendárias, por meio de suas respectivas administrações tributárias, não podem mais pensar a si mesmas sem pensar o ambiente que as circunda. $\mathrm{O}$ mundo, nesse caso, passa a ser visualizado como uma "sociedade de organizações", de modo que a análise organizacional feita por elas deve enfocar não apenas as suas estruturas internas (análise intra-organizacional) como também as suas interações com outras organizações (análise interorganizacional).

Com base numa abordagem de "sistema aberto", três elementos parecem ganhar relevo na discussão envolvendo a problemática da detecção: tecnologia, desenho organizacional e velocidade.

A questão da tecnologia, melhor dizendo, da tecnologia da informação, é quase que uma condição sine qua non, um ponto de partida, para se pensar um fisco eficiente/eficaz. Atrelada a ela está a questão da organização territorial dos entes fiscalizados, que por sua vez remete à questão do desenho organizacional das estruturas de fiscalização. A modelagem territorial de grandes contribuintes, muitas vezes abrangendo regiões geográficas distintas, aponta cada vez mais para uma necessária visão de solidariedade quanto ao exercício da fiscalização. Ambas as dimensões (tecnologia e design organizacional) estão vinculadas e delas depende diretamente a performance do vetor velocidade.

Resta ainda a questão do comércio eletrônico, via internet, que virtualiza cada vez mais o contribuinte em relação ao seu mercado de interesse (fornecedor ou consumidor), colocando a questão da velocidade em seu patamar mais alto e dramático. A constante desmaterialização de bens corpóreos e respectiva transformação em simples sistemas de informação, colocam um novo desafio para o poder público fiscalizador, especialmente no que tange à sua tarefa de detecção de uma eventual sonegação.

A performance da ação de detectar não pode ser avaliada de modo autônomo, visto que ela se relaciona com a performance dos outros desafios (diminuição, prevenção, legitimação e ética), influenciando-os e por eles sendo influenciada.

Um aumento da eficácia por parte de qualquer um dos outros desafios - diminuição da sonegação e/ou prevenção da sonegação e/ou legitimação do tributo e/ou conduta ética dos envolvidos - acarreta, evidentemente, uma atenuação do desafio da detecção, visto que a tomada de decisão de praticar o ato de sonegação tende a diminuir.

Por outro lado, um incremento na eficácia da ação de detectar possibilita uma melhoria dos resultados provenientes da performance dos outros desafios. Um caso óbvio é o do desafio da diminuição, favorecido à medida que o poder fiscalizador amplia a sua capacidade de detectar, muito embora tal condição não se configure como necessária e suficiente (do tipo causa-e-efeito), conforme será explicitado no próximo tópico.

Um aumento na eficácia de detectar pode também facilitar o desafio da prevenção, visto que aumenta o temor do ente fiscalizado em ter sua prática ilícita descoberta pelo poder fiscalizador. Favorece também, em face de um cenário que exibe pouco comprometimento social, a elaboração e 
efetivação mais rápida de medidas institucionais no sentido de se legitimar o tributo cada vez mais como ente socialmente instituído, atenuando, com isso, o desafio da legitimação.

Por fim, influencia diretamente o vetor ético de ambos os envolvidos (poder fiscalizador e ente fiscalizado). $\mathrm{O}$ aumento da capacidade de detectar não apenas pressiona (pelo temor de ter seu ilícito descoberto) o ente fiscalizado em termos da conduta que ele irá adotar, mas também ocupa com mais rapidez e transparência pontos estratégicos de sonegação, que em momentos pretéritos eram alvo de atitudes não éticas oriundas de uma competência fiscal praticada à margem do conhecimento e dos interesses do poder fiscalizador oficial .

\section{O DESAFIO DA DIMINUIÇÃO}

De início, o desafio da diminuição remete à idéia de se atuar sobre as sonegações individuais des-cobertas pela tarefa inicial da detecção, por meio de múltiplos "ataques", de modo a produzir o desejável efeito de uma gradativa diminuição do "quantum" global da sonegação praticada no respectivo território de atuação do tributo.

Por um lado, vale dizer que o desafio da diminuição não depende apenas da performance da detecção. O desafio da diminuição pode ter o seu caminho facilitado por uma eventual melhoria da performance dos outros três desafios (prevenção, legitimação é ética). Para tanto, basta que as ações ligadas à prevenção da sonegação e/ou legitimação do tributo e/ou conduta ética dos envolvidos apresentem algum tipo de evolução satisfatória em seus resultados, suficiente, por exemplo, para um eventual aumento do grau de cumprimento voluntário das obrigações tributárias, para que se tenha uma atenuação do desafio da diminuição.

Por outro lado, é importante ressaltar que uma melhoria da performance relacionada à ação de detectar sonegações individuais não implica, necessariamente, um aumento da eficácia da ação de diminuir a sonegação global pertinente ao território de atuação do tributo. A crença numa relação linear do tipo causa-e-efeito entre ambos os desafios, da detecção e da diminuição, em que a eficácia do primeiro é vista como condição necessária e suficiente para o alcance da eficácia do segundo, constitui uma simplificação do problema da sonegação.

Tal afirmação pode ser mais facilmente compreendida quando são focalizados os tributos cuja dinâmica se relaciona fortemente a fatores econômico-mercadológicos (caso do COFINS, PIS, CSSL, IPI, IRPJ, ICMS e ISS, mencionados anteriormente). Em face da condição de exercerem influência sobre a performance empresarial, tornam imperativo que os poderes fiscalizadores abandonem uma concepção "cartesiana", que visualiza as várias sonegações existentes como independentes e isoladas entre si, em prol de um enfoque " por sistemas".

A modelagem por sistemas (ou sistêmica) viabiliza, relativamente à modelagem cartesiana até então estabelecida, um novo contexto cognitivo amplificado e preocupado em entender cada fenômeno (a sonegação individual) a partir de um estudo de processos em múltiplos níveis de relacionamento e complexidade. Deixa-se de pensar o problema apenas em termos de partes e componentes isoladamente, para se levar em conta também uma preocupação com a organização e a ordem que as unifica, resultante da interação dinâmica das partes (BERTALANFFY, 1977).

De grande utilidade para a compreensão do que vem a ser um "sistema", e de como ele funciona na prática, é o conceito de holon, desenvolvido por Arthur Koestler. Ele criou a palavra holon para evidenciar o fato de que todo "sistema" constitui, na verdade, um subsistema, visto que tem sempre 
duas dimensões : pode ser considerado um "todo", no sentido de ser uma estrutura com lógica e finalidade próprias, e também "parte" de um "todo" maior, dotado de complexidade superior. Para Koestler, portanto, cada holon tem duas tendências opostas : uma tendência integrativa, que funciona como parte de um todo maior, e uma tendência auto-afirmativa, que preserva sua autonomia individual" (KOESTLER, 1978).

A abordagem por sistemas remete à idéia de se pensar a organização como um organismo, num processo contínuo de trocas com o ambiente (sistema aberto). Nesse enfoque, a organização é vista como um contínuo formado por quatro elementos básicos : entrada, transformação interna, saída e retro-alimentação. $\mathrm{O}$ conceito de abertura põe em relevo as relações-chave entre o ambiente e o funcionamento interno do sistema (MORGAN, 1996).

Ora, ao levar em conta o ambiente em termos de sua diversidade de formas, interações e propósitos, a visão por sistemas, aplicada ao universo dos contribuintes de um determinado espaço geográfico, permite inferir que estes têm por intento maior a competição e sobrevivência dentro de ambientes concorrenciais (círculos de concorrência), com interesses voltados para a ocupação/domínio/disputa de um espaço comum de mercado no que tange à colocação de seus produtos e definição da clientela. Destarte, pode-se dizer que cada contribuinte, do ponto de vista da sua sobrevivência no mercado, não obstante constitua em si mesmo uma unidade autônoma, integra também um grupo maior de contribuintes, cujos interesses comuns acarretam uma competição específica entre eles. A simples existência de uma empresa a condiciona, independentemente de sua vontade, a participar de um ou mais círculos de concorrência (com exceção, é claro, daqueles casos mais raros de monopólio).

O resgate do papel do ambiente, a nível das interações e propósitos, pelo pensamento sistêmico, permite a emergência da noção de organização. É ela que possibilita um olhar para o objeto de estudo como um ser dinâmico, dotado de vida própria, capaz de se auto-conservar e de evoluir para novas formas, notadamente quando sofre alguma influência do meio externo.

A título de exemplo, pode-se citar o caso de um contribuinte que pratique um certo "quantum" individual de sonegação e que, por algum motivo, retira-se do mercado (ou seja, do universo concorrencial) no qual está inserido. Ora, caso se trabalhe com a hipótese de que o seu círculo de concorrência básico pratique atos de sonegação, tem-se como razoável supor que as empresas remanescentes do respectivo círculo se apropriem daquele "mercado consumidor disponível" e estendam/ampliem para ele a eventual sone gação por elas já praticada. Isso significa, pois, que o "quantum" global de sonegação praticado pelo círculo de concorrência em questão pode não sofrer necessariamente uma diminuição pela supressão de um "quantum" individual de sonegação. Pode, inclusive, até aumentar, dependendo de quem irá ocupar aquele segmento de mercado em disponibilidade. Portanto, o que se percebe nesse caso é uma capacidade de acomodação da sonegação diante da nova situação, fruto de um típico processo de auto-regulação, evidenciando uma natureza comportamental encontrável em processos biológicos.

O exemplo citado revela, pois, o caráter falacioso inerente a uma crença determinista do tipo causa-e-efeito entre detecção e diminuição. Um aumento puro e simples da capacidade de detectar não significa necessariamente uma atenuação do desafio da diminuição. Isso significa que um combate à sonegação, sem a adoção de estratégias mais elaboradas (usando o conceito de sistema), pode resultar em ineficácia organizacional do ponto de vista das ações fazendárias. 
A visão por sistemas, por sua vez, traz uma nova resposta a nível do modus operandi fiscalizador. Trata-se, em outras palavras, de uma mudança de paradigmas que aos poucos começa a ocorrer no âmbito da atuação dos vários físcos existentes. Tal mudança tem a sua expressão maior com a chamada "Fiscalização Setorial", que busca atuar sobre os contribuintes individuais levando em conta a performance fiscal do setor econômico do qual ele faz parte (SAYEG, 2001).

As "Setoriais" não têm uma formulação pré-definida.. A "criatividade" surge como um ingrediente fundamental para a delimitação dos "recortes" que irão constituir as "Setoriais", podendose, talvez, antever que a eficiência/eficácia da ação do poder fiscalizador deverá estar relacionada a uma habilidade que pode ser entendida como uma questão de arte.

A referida habilidade é exigida por conta da complexidade do ambiente mercadológico. Uma empresa, muito embora participe a princípio de um círculo de concorrência que pode ser chamado de básico, na verdade participa de múltiplos círculos, pois o universo concorrencial corresponde a uma teia de relacionamentos, totalmente entrelaçados, de modo que não existe, a priori, um critério de delimitação. Acreditar na existência de um círculo de concorrência único e rigorosamente delimitável para cada empresa significa, mesmo sob a abordagem por sistemas, cair na armadilha cartesiana, que pressupõe qualquer objeto de estudo como um sistema fechado passível de ser "recortado" em partes menores e independentes entre si (método analítico). É a partir da variedade de "recortes" imaginados e realizados, que novos dados podem surgir, os quais quando organizados, podem se transformar em informações úteis à elaboração de estratégias pelo poder fiscalizador envolvido.

Cabe ressaltar que a modelagem por sistemas não está a salvo de ser objeto de outras formulações simplificadoras, de modo que todo cuidado é pouco. A título de exemplo, pode-se citar o risco de uma redução biológica, em que as sociedades humanas e os subprodutos de suas ações (por ex., a atitude de sonegar) acabem sendo completamente identificados com sistemas biológicos não humanos, tais como organismos e ecossistemas. Não se pode esquecer que o mundo humano, além de fazer uso de um intercâmbio de linguagem complexo, têm um grau máximo de autonomia, quando comparado a sistemas vivos não humanos.

\section{O DESAFIO DA PREVENÇÃO}

O desafio da prevenção busca refletir sobre dois aspectos importantes: a) acerca de uma forma de conscientização social, que viabilize cada vez mais a observância voluntária da lei pelos contribuintes; b) acerca do elo indissolúvel entre sonegação e legislação, dotando o ato de legislar de uma consciência preventiva relativamente às possibilidades de sonegação.

Com relação ao ítem "a”, podemos inicialmente mencionar a chamada a educação tributária voltada para o exercício da cidadania. Conscientizar significa, antes de qualquer coisa, informar. Explicitar para grandes contingentes populacionais qual o valor social do tributo e a importância do engajamento de cada indivíduo para um melhor funcionamento da vida humana em sociedade é, sem dúvida, de grande importância.

De pouco efeito imediato, paradoxalmente a educação tributária parece ser a vertente que pode oferecer melhores resultados a longo prazo. Isso porque a educação tributária permite interferir no ethos (disposição interior, maneira de se comportar) de toda uma gama de indivíduos, toda uma geração. Muito embora esteja restrita à questão do tributo, pode-se dizer que a educação tributária contribui para um repensar de cada indivíduo relativamente ao seu papel social. $\mathrm{O}$ conceito de cidadania possibilita uma ampliação da concepção que o indivíduo tem dele mesmo, passando a se ver 
não mais como indivíduo (entendido como ser individual, isolado), mas como cidadão ativo e solidário (GAMA,2000), sujeito de direitos e deveres.

A condição de "cidadão ativo" aponta para um indivíduo que age e se organiza no sentido de influenciar as decisões tomadas pelo poder público. O sentimento cada vez maior de ser coparticipante das decisões do aparato governamental possibilita, concomitantemente, que o indivíduo (no âmbito de sua vida pessoal) se reconheça como um subproduto social, co-produzido pelo Estado. Talvez a conseqüência mais importante deste fato seja uma ampliação da capacidade psíquica individual para entender que a multiplicidade de fatos cotidianos isolados da vida humana em sociedade (como, por exemplo, as várias formas de violência) têm uma forte componente social, da qual ele próprio é co-responsável.

A condição de "cidadão solidário", por sua vez, representa um passo complementar, para além da condição de "cidadão ativo". Isso porque a condição de "ativo" pode ainda se dar a serviço de interesses corporativistas, privilegiando grupos sociais específicos. Por outro lado, a idéia de "solidariedade" representa, a nosso ver, um golpe profundo no modelo de racionalidade vigente. Ela abre espaço para uma convivialidade que faça também referência a outros valores, distintos daqueles que regem a lógica de mercado. No caso da "solidariedade", trata-se de uma "preocupação com o outro" como valor pessoal, o qual possibilita uma discussão ampla (de caráter nacional) sobre as prioridades na redistribuição dos recursos em mãos do poder público.

Ainda com relação ao ítem "a”, que trata de uma observância voluntária da lei pelos contribuintes, pode-se também citar o caso das técnicas de fiscalização que buscam trabalhar tendo em vista um enfoque informativo, preventivo, em que o fisco opta, pelo menos inicialmente, por deixar de lado um enfoque punitivo em prol de uma atitude espontânea do ente fiscalizado no sentido de elevar a sua arrecadação de tributos. Esse caminho possui a vantagem de exibir ao ente fiscalizado a imagem de um fisco ágil e bem informado.

Com relação ao ítem "b", trata-se compreender o caráter indissociável entre sonegação e legislação. Isso porque a sonegação só pode se dar a partir de um referente, de uma origem, que no caso é a própria legislação. Seja pelo desvio (à norma) ou pela brecha existente no texto legal, a sonegação somente se produz a partir de um ordenamento prévio (legislação).

A dimensão profunda que aqui se estabelece é a relação dialógica (lógica de opostos) entre ordem e desordem. A ordem é co-produtora da desordem e vice-versa. Não apenas a desordem (sonegação) se produz a partir da ordem (legislação), mas também ocorre o contrário. As alterações na norma também se dão por revisão, na forma de adição/subtração/substituição, tendo em vista os efeitos práticos da produção da desordem (sonegação).

O entrelaçamento entre sonegação e legislação sempre irá existir. É simplesmente impossível se pensar uma completa racionalização do real a ponto de romper com o elo entre legislação (ordem) e sonegação (desordem). Todavia, a "co-produção" de sonegação deve ser minimizada. Para tal, é preciso legislar e ao mesmo tempo ser capaz de antever os riscos dessa legislação.

Pensar apenas o "estado de direito", a norma, sem pensar no seu oposto, significa cair na armadilha de um princípio explicativo (do real existente) centrado na idéia de ordem, que se instalou no corpo de várias ciências da natureza no passado e acabou sendo transplantado para o campo antropossocial (MORIN,1977). No âmbito dessa forma simplificada de conceber o real, só há lugar para a ordem e tudo o mais que com ela se relaciona, tal como, por exemplo, a idéia de lei. O conceito 
de desordem, nesse contexto, é concebido como um dejeto, um pequeno detalhe, um desvio, que não faz parte do curso "normal" das coisas. Um entendimento que busca, a princípio, pensar o objeto apenas em termos da ordem que o rege ou em que ele se insere.

Ora, pensar a legislação de algum tributo exige dos atores sociais envolvidos um esforço permanente no sentido de pensar o ordenamento legal simultaneamente às possibilidades de sua transgressão. Não se tem dúvida de que isso seja já uma preocupação (e que, inclusive, sempre o tenha sido), porém, acredita-se, de forma muito pouco relevante face àquela voltada para a elaboração do ordenamento legal propriamente dito. Este último ainda é, essencialmente, tratado/concebido como algo em si, separado do meio externo que tenta "pervertê-lo". A escala em que isso ocorre depende, sem dúvida, do grau de penetração psíquica da idéia de ordem como um paradigma explicativo do real.

A habilidade de pensar a ordem (legislação) por meio de um processo que inclui uma concomitante reflexão sobre as possíveis interferências da desordem (sonegação) naquele ordenamento deve ser vista como um ingrediente necessário para o contínuo fortalecimento do próprio ordenamento legal. Portanto, as possibilidades de desvios e brechas à legislação devem estar sempre sendo pensadas com a mesma ênfase com que é pensada a própria legislação. Os legisladores devem estar conscientes do círculo vicioso que "ajudam” a estabelecer (dialógica entre legislação e sonegação).

O desafio da prevenção, tendo em vista a sua característica marcante de ser, fundamentalmente, uma busca por conscientização nas várias dimensões em que se faz presente - na sociedade em geral (pela educação tributária), nos entes fiscalizados (pela ação fiscal via acompanhamento, inicialmente não repressivo) e no poder público (consciência dialógica no ato de legislar) -, influencia, naturalmente, a performance de todos os outros desafios (detecção, diminuição, legitimação e ética).

A interação com os dois primeiros desafios citados, detecção e diminuição, é praticamente óbvia. Quanto mais penetrante for o trabalho múltiplo de conscientização levado a cabo pelo desafio da prevenção, mais se tende a inibir atos de sonegação, atenuando, com isso, os trabalhos fiscais de detecção e as chances da sonegação global de um dado território se manter ou mesmo crescer.

A interação mais forte e mais interessante se dá, todavia, entre o desafio da prevenção e o desafio da legitimação. Esses dois desafios estão de tal forma associados que, dependendo dos resultados alcançados por um deles, a performance do outro pode ser alavancada ou mesmo se tornar um fracasso. Uma performance ineficaz do desafio da legitimação pode, por exemplo, inviabilizar o alcance de bons resultados a longo prazo com a conscientização pela educação físcal e a curto prazo pela fiscalização preventiva (via acompanhamento), que busca um aumento espontâneo de arrecadação. Por outro lado, a ausência de um cenário de resistência à prática da sonegação, causado pela supressão ou diminuição (por exemplo, por falta de verbas) de ações voltadas a prevenir a sonegação, constitui, por sua vez, um cenário desestimulante a iniciativas no sentido de se buscar cada vez mais a legitimação do tributo junto à sociedade.

Por fim, cabe mencionar a interação entre os desafios da prevenção e da ética. O desafio da ética é um desafio voltado para uma conscientização acerca do comprometimento de cada indivíduo relativamente a questões de ordem coletiva. Ora, a ação de prevenir a sonegação por meio da educação tributária constitui, ela própria, um esforço no sentido de um aprimoramento ético. Já a ação de prevenir a sonegação por meio de um acompanhamento fiscal, mesmo tendo algum sucesso, na forma de um aumento espontâneo da arrecadação, não garante que a atitude do ente físcalizado provenha de um aprimoramento ético. Ela pode ter se originado muito mais de um temor ante a uma possível ação 
repressiva por parte do poder público fiscalizador, do que de uma conduta pautada por um eventual resgate do vetor ético.

A questão que cerca a consciência dialógica entre sonegação e legislação é, talvez, a mais dramática, dentre as ações de prevenção, do ponto de vista da interação com a ética. Isso porque a ausência do vetor ético no processo de produção da legislação comp romete seriamente qualquer análise da dialógica entre legislação e sonegação.

\section{O DESAFIO DA LEGITIMAÇÃO}

O desafio da legitimação busca dar legitimidade ao tributo enquanto ente socialmente instituído, no âmbito de um processo contínuo e permanente.

Um tributo se impõe como legítimo quando a relação custo-benefício é avaliada como satisfatória pelo grupo social sobre o qual incidiu a tributação. Via de regra visto pelos entes tributados como um ônus, face à predominância de um interesse individual mensurável hic et nunc relativamente a um interesse social encarado como distante e abstrato, o tributo pode ter essa imagem alterada desde que, ambos os envolvidos, governo e sociedade, trabalhem juntos no sentido de propiciar que a função social do tributo se exerça de forma mais plena, ou seja, mais próxima da proposta que se encontra na origem do ato de tributar.

A sociedade, formada pelos entes tributados e pelos cidadãos em geral, tem um papel importante a cumprir e, ao que tudo indica, não parece estar consciente dele. Conforme já mencionado, a questão passa pela necessidade de uma educação tributária que resgate o conceito de cidadão relativamente à questão da geração e uso dos recursos públicos via tributação. Em outros termos, trata-se de conscientizar cada indivíduo de seus direitos e deveres na geração e destinação dos recursos públicos obtidos via tributação.

No caso do ente tributado, faz-se importante uma revisão do termo "contribuinte", uma vez que ele contribui claramente para uma distorção quanto ao entendimento da interação governo/sociedade do ponto de vista tributário. O termo "contribuinte" é geralmente definido nos dicionários como aquele que paga contribuições. Em perfeita sintonia com tal significado, está o termo inglês "taxpayer", que pode ser entendido como uma adição de dois conceitos : pagador (payer) + contribuição (tax).

Ora, o conceito de "contribuinte" ocasiona um inconveniente no contexto das relações sociais. Ao enfocar literalmente o ente tributado como alguém que cumpre uma mera função de contribuir para a geração das finanças públicas, ele viabiliza uma visão unidimensional da interação entre sociedade e poder público: ao ente tributado cabe apenas o dever de contribuir, enquanto ao ente tributante cabe apenas o direito de receber. Nessa perspectiva, o poder público tem, no máximo, o dever de fiscalizar, previsto em lei, para garantir o seu direito de receber. Com isso, fica negligenciado o outro lado da relação entre sociedade e Estado, a saber : o direito do indivíduo/ente tributado de receber/exigir do Estado, em retorno, benefícios na forma de serviços públicos prestados com qualidade, e da parte do Estado, é claro, o dever de prestá-los em tais condições, possibilitando uma real melhoria das condições de vida da população.

No Brasil, a compreensão redutora que permeia a relação entre sociedade e Estado adquire um caráter cada vez mais dramático quanto às possibilidades de sua transposição. O motivo para tal reside na crescente descrença por parte dos indivíduos relativamente ao Estado como instituição capaz de cumprir o seu papel social. Apesar de todos os seus esforços, e de alguns indicadores a seu favor, a 
relativa inércia do poder público na área social faz com que fique cada vez mais distante da mente individual a consciência de exigir seus direitos como legítimo destinatário dos recursos públicos.

De outro lado, tem-se o governo, que precisa dar sinais constantes de eficiência/eficácia na administração e uso do dinheiro público. Fatores como desperdício no uso do dinheiro público, assim como manipulação daquele à margem dos interesses da maioria da população, contribuem ambos de modo negativo para a imagem do poder público, causando riscos sérios de regressão na luta pela legitimação do tributo. A administração e o uso do dinheiro público por parte do governo formam, na verdade, um circuito recorrente relativamente à participação dos indivíduos/entes tributados na geração do erário público. Sinais evidentes de má administração e de mau uso do dinheiro público, por parte do governo, tendem a estimular (e mesmo a serem usados como argumentos para) ações de sonegação. Inversamente, atos de sonegação fazem com que o governo, não raras vezes, precise manter e até mesmo aumentar a carga tributária a fim de fazer frente aos investimentos e desafios sociais.

Afora o problema da geração e uso social do tributo, tem-se também a questão da carga tributária. A legitimidade do "quantum" tributário estabelecido pela legislação pressupõe transparência não apenas das necessidades do poder público para fazer frente aos seus compromissos visando o bem-estar social, como também dos indivíduos/entes tributados, para fazerem frente às suas necessidades de competição e/ou sobrevivência. Tal transparência, à medida em que comece a tomar corpo, tende a funcionar como elemento capaz de agir contra a simplificação que abarca ambas as visões do problema, expressas tanto por governo como pela sociedade. Por um lado, combate a visão redutora do governo, representado pelo poder fiscalizador, que via de regra reduz o problema complexo da sonegação a uma questão de natureza apenas ético-comportamental. Por outro lado, combate a visão redutora do ente tributado, que via de regra reduz o problema complexo da sonegação a uma questão apenas de carga tributária (visão estritamente quantitativa).

A interação do desafio da legitimação com os outros desafios é evidente. Todo avanço no sentido de uma maior aceitação/compreensão da função social do tributo representa sempre uma barreira ao desejo de sonegar, atenuando, com isso, os desafios da detecção, diminuição e da ética. Mas, acima de tudo, a interação mais próxima se verifica relativamente ao desafio da prevenção, conforme mencionado no tópico anterior.

\section{O DESAFIO DA ÉTICA}

O desafio da ética lida, na sua essência, com uma questão comportamental. Entretanto, o comportamento humano individual encontra-se intimamente relacionado com uma visão de mundo que impera socialmente num determinado mo mento no tempo, de modo que qualquer esforço no sentido de pensar as ações humanas individuais e seu encaixe num determinado ordenamento social impõe o resgate de uma dimensão histórica.

No contexto civilizatório pré-moderno, as chamadas civilizações superiores estavam identificadas com um sistema de castas, tendo por base uma vinculação do poder político (Estado) com o poder religioso (Igreja). A "hierarquia" e o "sagrado" constituíam, pois, os alicerces valorativos fundamentais. O individualismo, àquela época, se caracterizava como um "individualismo-fora-domundo" (DUMONT,1985), oriundo da mensagem cristã que faz da salvação da humanidade a salvação do indivíduo humano. Prevalecia uma valorização do indivíduo em sua relação com Deus, paralelamente a uma desvalorização do mundo real existente. Em tal contexto, qualquer ato humano 
que violasse o ordenamento social adquiria contornos delimitados, sendo traduzido como um rompimento do indivíduo em sua própria relação filial com Deus.

A partir da era moderna, com a separação entre Estado e Igreja, e a construção de uma esfera autônoma do econômico, as ações individuais passam por uma dessacralização, dando origem a um "individualismo-dentro-do-mundo" (DUMONT,1985). A elevação da "economia de mercado" à condição de paradigma regulador dos negócios humanos na era do capitalismo industrial se verifica em meio a uma visão de mundo cujo valor essencial é a busca permanente de bem-estar material.

Tal concepção materialista de mundo é levada a termo, por sua vez, em consonância com uma racionalidade própria, de caráter essencialmente instrumental, uma vez que negligencia quaisquer outros fỉns que não sejam aqueles voltados para a lógica da utilidade e do lucro. A principal decorrência perversa do predomínio dessa racionalidade é que o "indivíduo médio" da era moderna tem suas aptidões diminuídas no sentido de emitir julgamentos valorativos independentes de expectativas de sucesso pessoal e momentâneo (RAMOS, 1981).

É preciso se reconhecer que os grilhões do passado (era pré-moderna) viabilizavam que cada indivíduo, naquele contexto, se sentisse antes um "ser social" do que um "ser individual", uma vez que encontrava-se inserido em uma cultura que valorizava em primeira instância a ordem e a conformidade individual à totalidade social. A partir da era moderna, por sua vez, com a ausência de delimitadores (à moda pré-moderna) e a efetivação do "individualismo" como forma fundamental de síntese social, onde o "ser individual" prevalece em relação ao "ser social", cria-se um espaço propício para a disseminação de ações à margem do ordenamento coletivo, voltadas para a consecução de interesses pessoais.

O problema gerado a partir de uma possível conduta pautada por uma inadequação às regras sociais se estende a todos os atores do cenário social contemporâneo. É verdade que em alguns países a ação humana voltada para o desregramento pode ocorrer em menor escala, face a um sentimento holista mais presente em cada cidadão - seja por razões de caráter histórico-cultural, seja pelo temor causado pela existência de mecanismos mais eficazes de controle social (p. ex., uma legislação penal severa). Entretanto, não há como imaginar qualquer cenário estável, sem um constante esforço no sentido de evitar/combater o surgimento de ações contrárias ao ordenamento social.

No contexto da sonegação tributária, o desafio da ética envolve a todos - tanto sociedade, representada pelo ente fiscalizado, como também poder público, representado simultaneamente pelos poderes administrador, legislador e fiscalizador. Da parte do poder público, a busca por um enquadramento ético cada vez maior se operacionaliza por uma conscientização crescente de seus membros acerca de sua missão social, assim como pela intensificação da normatização de procedimentos e da transparência de suas ações, instrumentalizadas estas últimas por critérios técnicocientíficos cada vez mais rigorosos.

Da parte do ente tributado, entretanto, a questão é mais delicada. Não é raro um contribuinte alegar que su comportamento tributário encontra-se sobredeterminado pela conduta adotada por outros contribuintes que participam de seu universo concorrencial, principalmente por parte daqueles que integram o seu círculo de concorrência básico. Tomando por base a teorização por sistemas, não é absurdo conceber que, com base na competição existente no seio dos círculos concorrenciais, condutas sonegadoras individuais possam ter o seu espectro de ação ampliado, multiplicado, para outros contribuintes, a partir de um processo de "realimentação positiva", fruto da necessidade de uma 
"adaptação" (auto-regulação, homeostase) desses outros contribuintes às novas circunstâncias ambientais.

Ora, se o exercício da ética for entendido como uma capacidade de discernimento (entre o bem e o mal) que pressupõe uma elasticidade de escolha, temos que o exercício da ética, neste caso, pode estar parcialmente comprometido. Recoloca-se aqui a questão da "justiça físcal", onde se torna preponderante a eficiência/eficácia do poder fiscalizador no sentido de uma performance que, de alguma forma, seja capaz de influenciar/atingir simultaneamente a conduta de todos os envolvidos em um determinado círculo de concorrência básico que esteja sendo alvo de fiscalização.

Na origem, a sonegação é e nunca deixará de ser um problema que possui uma dimensão ética, indissociável de uma racionalidade utilitarista voltada para a busca objetiva de bem-estar material a nível individual, ainda que em detrimento do bem-estar coletivo. Entretanto, como processo já instalado/disseminado na tessitura do cenário mercadológico, a dimensão profunda da sonegação está em se reconhecer o grau de autonomia dela em relação ao ambiente de sobrevivência/competição das empresas. Quanto maior for esse grau de autonomia, maior o desvio ético. A chamada "indústria da sonegação", em que a mesma constitui um ente autônomo posto a serviço de alguns, interessados apenas em se beneficiar lesando o erário público, expressa, sem dúvida, o desvio ético máximo, uma vez que, com ela, a sonegação alcança o seu maior grau de autonomia.

\section{CONCLUSÕES}

Muito embora tenha sido feito uso de um modelo reflexivo que, de início, parecia apontar na direção de uma metodologia "cartesiana" de análise, já que o desafio macro da sonegação dos tributos envolvidos foi subdividido em cinco desafios menores, aparentemente independentes, percebe-se, todavia, ao longo do artigo, que os princípios do cartesianismo não se aplicam ao caso em tela.

Os cinco desafios, longe de constituírem partes independentes e isoladas umas das outras, cuja reunião comporte o problema da sonegação em sua totalidade, pelo contrário, apresentam-se como linhas de ação com performances intimamente correlacionadas. Pode-se dizer que as referidas performances influenciam/penetram/realimentam (positiva ou negativamente) umas às outras, no âmbito de uma rede de relações não lineares que, por sua vez, inviabilizam qualquer hipótese de uma delimitação nítida do campo de atuação de cada desafio individual e de alguma previsibilidade mais segura e de curto prazo quanto a resultados.

Essa compreensão acerca da impossibilidade do trato da questão da sonegação por uma via cartesiana é, sem dúvida, o elemento fundamental para um entendimento e valorização da complexidade como abordagem. Ao contrário do cartesianismo, no qual o caminhar é previamente traçado, a complexidade destaca exatamente o contrário: uma busca/luta sem fim, em múltiplas frentes, fazendo o seu caminho no próprio caminhar.

Acreditar numa saída única como solução para o problema da sonegação, como crê o pensamento que se expressa por redução, significa tornar-se prisioneiro de uma visão social centrada na idéia de "ordem". Tal fato se dá independentemente da origem do pensamento redutor, de modo que pouco importa se a origem da redução provém do poder público tributante ou da sociedade fiscalizada. Seria acreditar ingenuamente numa eliminação do conflito de interesses existente no seio da interação indivíduo/Estado, cuja performance tem uma dimensão histórica que rejeita uma permanência do momento e não tem como ser banida do cenário da vida humana em sociedade. 
A interação entre indivíduo e Estado configura uma relação que simultaneamente se verifica como complementar e como antagônica. Complementar, por um lado, quando se pensa o capitalismo moderno em termos da idéia de que os vícios individuais se transformam em virtudes coletivas, gerando bem-estar social. Antagônica, por outro lado, quando se revela, no âmbito dessas mesmas relações capitalistas, que alguns desses vícios individuais podem ter uma outra face, não necessariamente favorável aos interesses coletivos, como é o caso, por exemplo, de uma conduta pautada pela sonegação de tributos.

\section{Artigo recebido em 19/02/2002. Aprovado em 04/07/2002.}

\section{REFERÊNCIAS BIBLIOGRÁFICAS}

BERTALANFFY, Ludwig Von. Teoria Geral dos Sistemas. Rio de Janeiro, Vozes, $3^{\text {a }}$ edição, 1997.

CHIAVENATO, Adalberto. Introdução à Teoria Geral da Administração. São Paulo, Makron Books, $4^{\mathrm{a}}$ edição, 1993.

COMTE, Auguste. “Discurso sobre o espírito positivo”. In: Os Pensadores. São Paulo, Abril, 1983.

DESCARTES, René. “Discurso do Método”. In: Os Pensadores. São Paulo, Nova Cultural, 5ª edição, 1991.

DUMONT, Luis. O individualismo. Rio de Janeiro, Rocco, 1985.

GAMA, Heleny U. ; Souza, Cassio R.J. Cidadania, Educação e Finanças Públicas. São Paulo, Folha do Fazendário, janeiro, 2000 (uma publicação mensal da Secretaria da Fazenda do Estado de São Paulo).

KOESTLER, Arthur. Janus. Londres, Hutchington, 1978.

KUHN, Thomas. A Estrutura das Revoluções Científicas. São Paulo, Perspectiva, 1987.

MORGAN, Gareth. Imagens da Organização. São Paulo, Atlas, 1996.

MORIN, Edgar. O Método I: a natureza da Natureza. Lisboa, Europa-América, 1977.

RAMOS, Alberto Guerreiro. A Nova Ciência das Organizações. Rio de Janeiro, FGV, 1981.

SAYEG, Roberto N. Paradigmas em mudança no fisco estadual paulista. De Descartes à visão por sistemas. São Paulo, Folha do Fazendário, janeiro, 2001 (uma publicação mensal da Secretaria da Fazenda do Estado de São Paulo).

SENGE, Peter M. A Quinta Disciplina. São Paulo, Best Seller, 6ª edição, 2000. 